\title{
FABRICATION OF HIGHLY DENSE PURE 6H-SiC CERAMICS VIA THE PVT METHODUSING SUB-MICRON SIC POWDERS
}

\author{
${ }^{\#}$ BOBO LIU, JIANFENG YANG \\ State Key Laboratory for Mechanical Behavior of Materials, Xi'an Jiaotong University, \\ $X i^{\prime}$ an 710049, PR China \\ "E-mail: yupiner2003@163.com
}

Submitted July 4, 2019; accepted November 19, 2019

\begin{abstract}
Keywords: Sub-micron SiC, Dense ceramics, Polycrystalline phase, PVT method
The dense SiC ceramics were prepared by the physical vapour transport (PVT) method using three types of SiC powder with different grain size, including a kind of SiC powder with a mean diameter of $500 \mathrm{~nm}$. The effects of the grain size of the raw materials on the bulk density, bending strength and hardness of the SiC ceramics were studied. It was found that with a decreasing grain size, the bulk density and the bending strength of the fabricated SiC ceramics increased, while the Vickers hardness decreased. the effects of the grain size of the raw materials on the nucleation density and the growth rate of the $\mathrm{SiC}$ were analysed, and the growth characteristic of the SiC ceramics was systematically explored. The results indicated that the crystal type, the nucleation density and the growth rate were obviously affected by the soaking temperature. When the temperature was higher or lower than $2200{ }^{\circ} \mathrm{C}$, the fabricated ceramics was composed of a $6 \mathrm{H}-\mathrm{SiC}$ polycrystalline or the mixture of a $6 \mathrm{H}-\mathrm{SiC}$ and $3 \mathrm{C}-\mathrm{SiC}$ polycrystalline. Meanwhile, with an increasing temperature, the nucleation density decreased and the growth rate increased. Obviously, by optimising the fabrication process, highly dense $6 \mathrm{H}-\mathrm{SiC}$ ceramics with a bulk density of $3.07 \mathrm{~g} \cdot \mathrm{cm}^{-3}$ and a bending strength of $335.6 \pm 10 \mathrm{MPa}$ could be rapidly fabricated by the PVT method using the sub-micron SiC powder.
\end{abstract}

\section{INTRODUCTION}

Dense silicon carbide $(\mathrm{SiC})$ ceramics have been one of the most widely used high-performance structural components, owing to their high temperature strength, corrosion resistance, good thermal conductivity, oxidation resistance, and relatively low thermal expansion coefficient $[1,2]$. However, its large-scale industrial application was always hindered due to the lack of highlyperformance density SiC ceramics [3-6]. Recently, a range of synthesis methods (such as the reaction sintering method, the hot-pressing sintering process, and the liquid-phase sintering technique) were reported for the fabrication of dense $\mathrm{SiC}$ ceramics by the sintering of $\mathrm{SiC}$ powders with the help of functional additives [8-9]. These traditional methods have the advantages of colder sintering temperatures $\left(\sim 1400{ }^{\circ} \mathrm{C}\right)$, high yield and low cost, and can be applied in an industrial production setting. Unfortunately, the remnants (sintering additives) might remain in the final products, which has a "weak" secondary phase, seriously degrading the excellent properties of the high-density $\mathrm{SiC}$ ceramics.

Additionally, it is very difficult to obtain high-density $\mathrm{SiC}$ ceramics without sintering additives, due to the covalent nature of the $\mathrm{Si}-\mathrm{C}$ bonding and the low selfdiffusion coefficient $[15,16]$. Lately, Dai's group reported a novel physical vapour deposition (PVT) method for the preparation of pure $\mathrm{SiC}$ ceramics. However, many problems remain to be solved. In the previous work, high-purity and high-density $\mathrm{SiC}$ ceramics were successfully fabricated by the PVT method [17]. The growth rate and the orientation of the $\mathrm{SiC}$ ceramics, the effects of the growth time and temperature on the grain size were explored.

However, the $\mathrm{SiC}$ ceramics only exhibited a bending strength of $290 \pm 34 \mathrm{MPa}$ because of the larger grain size (an average grain size of $2 \mathrm{~mm}$ ). According to the fine grain strengthening mechanism, by decreasing the grain size it might be a potential way to increase the bending strength of the high-density SiC. On the basis of the theories of crystal growth, the primary reason for being responsible for the large crystal size was the low supersaturation which is beneficial to form the low-density nucleus of the $\mathrm{SiC}$. On the contrary, large super-saturation in the growth chamber of high-density $\mathrm{SiC}$ facilitates the formation of a high-density nucleus which is good for obtaining the smaller grain size $\mathrm{SiC}$ by restricting the lateral growth of each nucleus. The latest research in the literature demonstrated that the smaller grain size of the raw materials could increase the super-saturation in the growth chamber. Therefore, in this study, with the aim of increasing the mechanical property of the high-density $\mathrm{SiC}$ ceramics, nano $\mathrm{SiC}$ powders $(500 \mathrm{~nm})$ were used as the raw material to fabricate high-density SiC by PVT, 
and the effects of the nano $\mathrm{SiC}$ powder on the growth of $\mathrm{SiC}$ ceramics have been studied. It was found that the nucleation habits of high-density $\mathrm{SiC}$ have been refined, and its bending strength increased with the grain size of the raw materials decreasing as well.

\section{EXPERIMENTAL}

\section{Raw materials}

Commercial $\mathrm{SiC}$ powders of $175 \mu \mathrm{m}$ (purity, $99.90 \%$; specific surface area, too small to test; Zaozhuang Liyuan SiC Co. Ltd., Zaozhuang, China), $50 \mu \mathrm{m}$ (purity, $99.90 \%$; specific surface area, $0.018 \mathrm{~m}^{2} \cdot \mathrm{g}^{-1}$; Zaozhuang Liyuan SiC Co. Ltd., Zaozhuang, China) and $500 \mathrm{~nm} \mathrm{SiC} \mathrm{powders} \mathrm{(purity,} 99.81 \%$, specific surface area, $20.012 \mathrm{~m}^{2} \cdot \mathrm{g}^{-1}$, Shanghai ST-nano science and technology Co. Ltd., China) were used as the raw materials, which were homogeneously mixed. The particle size of the different raw materials was measured by a Laser Particle Size analyser (Winner3003). Figure 1 shows that three particle size distributions of the raw material measurements, the particle size of the sub-micron materials has a probability distribution average at $500 \mathrm{~nm}$. The same quality of the three types of silicon carbide raw materials were placed into the same graphite crucible at $2200{ }^{\circ} \mathrm{C}$ for $30 \mathrm{~min}$. The results utilisation is shown in Table 1, it is the ratio of the graphite deposition on the substrate and the original weight. It can be seen that the utilisation increased with a decrease in the size of the raw materials, the utilisation of the sub-micron powders is 0.387 maximum. With the same sintering temperature, because of the large specific surface area of the sub-micron powder, the saturation vapour pressure, rapid evaporation rate and large growth rate can be seen. In the action, it is more economical to choose the submicron silicon carbide as the raw material.

\section{Fabrication process}

The density of the $6 \mathrm{H}-\mathrm{SiC} \mathrm{SiC}$ ceramics was prepared by the physical vapour transport (PVT) method at different temperatures $\left(1900{ }^{\circ} \mathrm{C}, 2000{ }^{\circ} \mathrm{C}, 2100{ }^{\circ} \mathrm{C}\right.$, $2200{ }^{\circ} \mathrm{C}, 2300{ }^{\circ} \mathrm{C}$ ) using $175 \mu \mathrm{m}, 50 \mu \mathrm{m}$ and $500 \mathrm{~nm}$ $\mathrm{SiC}$ powders as the raw materials, respectively. The effects of the temperature and holding time on the grain size, growth rate, thickness and orientation of the silicon carbide were explored, and the concentration gradient, the random nuclei of the $\mathrm{SiC}$ on the polycrystalline phase

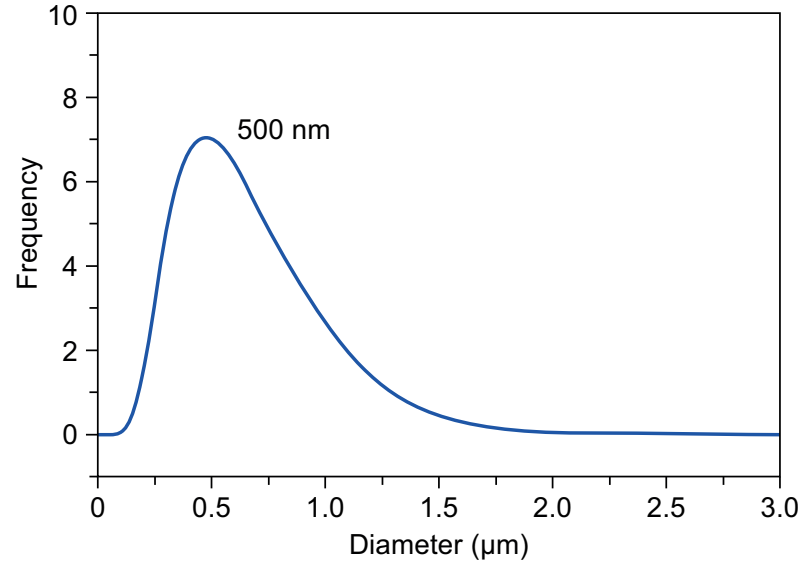

a)

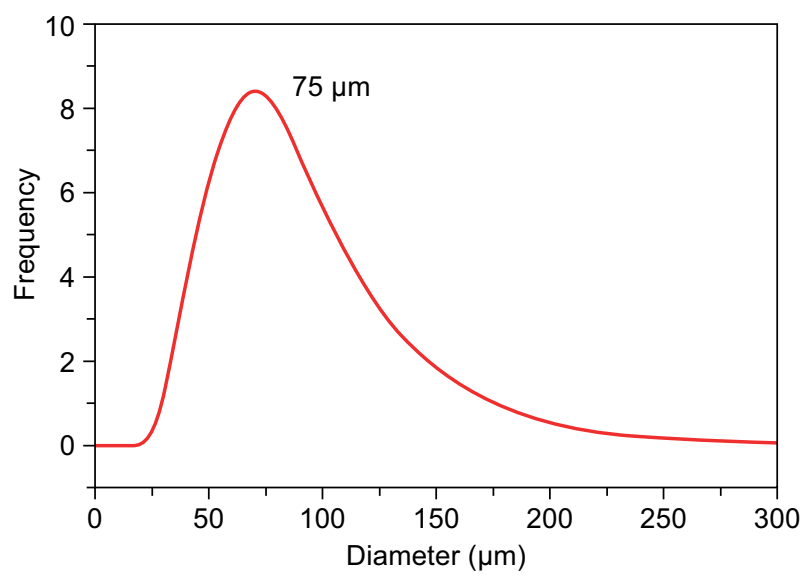

b)

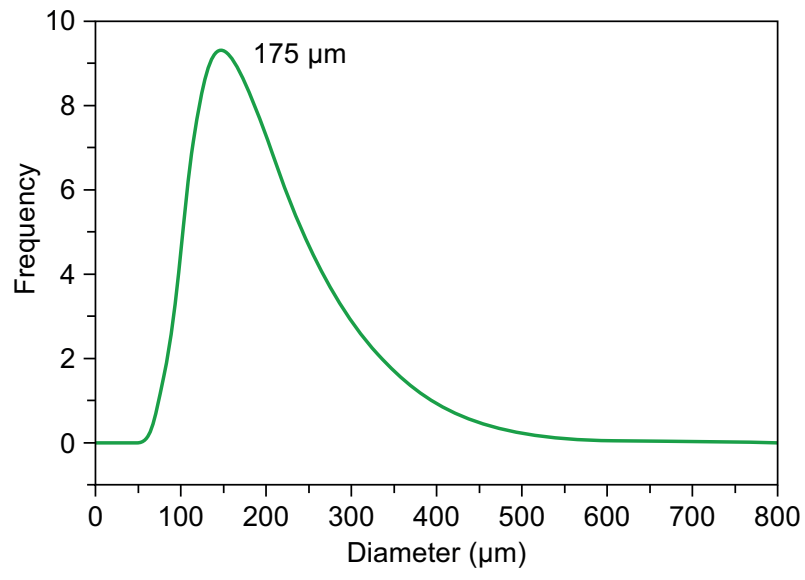

c)

Figure 1. The measurements of the three particle size distribution of the raw powders.

Table 1. The results of the utilisation.

\begin{tabular}{lccccc}
\hline & $\begin{array}{c}\text { Raw weight } \\
(\mathrm{g})\end{array}$ & $\begin{array}{c}\text { Residual } \\
(\mathrm{g})\end{array}$ & $\begin{array}{c}\text { Deposition on lid } \\
(\mathrm{g})\end{array}$ & $\begin{array}{c}\text { Loss } \\
(\mathrm{g})\end{array}$ & $\begin{array}{c}\text { Utilisation } \\
(\%)\end{array}$ \\
\hline $500 \mathrm{~nm}$ & 3 & 0.85 & 1.16 & 0.99 & 38.7 \\
$75 \mu \mathrm{m}$ & 3 & 1.80 & 1.09 & 0.11 & 36.3 \\
$175 \mu \mathrm{m}$ & 3 & 1.03 & 1.01 & 0.96 & 33.7 \\
\hline
\end{tabular}


growth during the SiC PVT growth were studied. The growth process consisted of the following steps: At first, the furnace was heated to $1273 \mathrm{~K}$ and held for $10 \mathrm{~min}$ at a pressure of about $10^{-3} \mathrm{~Pa}$ to volatilise the contaminated gas species. Then, argon with a pressure of $50 \mathrm{kPa}$ was charged into the furnace and then the temperature was gradually increased to the growth temperature. The temperature of the bottom of the crucible was increased to $2200 \pm 10{ }^{\circ} \mathrm{C}$. Finally, the temperature at the bottom of the crucible was kept at the growth temperature and the system pressure of the argon gas was kept at $5 \times 10^{4} \mathrm{~Pa}$. After growth, the polycrystalline $\mathrm{SiC}$ specimen with $100 \mathrm{~mm}$ in diameter and $8 \mathrm{~mm}$ in thickness could be prepared, and green $\mathrm{SiCw}$ could be obtained in the heat radiation holes of the upper carbon fibre felt.

\section{Characterisation techniques}

The phase formation of the specimens was analysed by $\mathrm{X}$-ray diffraction using $\mathrm{Cu} \mathrm{Ka}$ radiation. The microstructure was observed using a scanning electron microscopy system (JEOL JSM-6460). The average grain size was estimated by the Image-Pro Plus quantitative image analysis software (Version 7.0, Media Cybernetics, USA). The densities of the specimens were determined by the Archimedes method. The bending strengths of the specimens were tested via a three-point bending test (Model WDT-10) with a support distance of $20 \mathrm{~mm}$, a crosshead speed of $0.5 \mathrm{~mm} \mathrm{~min}^{-1}$ and the test including three samples, respectively. The Vickers hardness was tested with a load of $9.8 \mathrm{~N}$ using the OmniMet 88-7000 fully automated micro-indentation.

\section{RESULTS AND DISCUSSION}

The effects of the grain size of the raw materials on the mechanical properties of the $\mathrm{SiC}$ ceramics

The mechanical properties of the $\mathrm{SiC}$ ceramics are listed in Table 2. The specimens exhibited very high bulk density and hardness. The bulk density of the sample using the $500 \mathrm{~nm}$ powders is $3.197 \mathrm{~g} \cdot \mathrm{cm}^{-3}$, which is very close to the theoretical density of the $\operatorname{SiC}\left(3.211 \mathrm{~g} \cdot \mathrm{cm}^{-3}\right)$ and much higher than the density of the samples using $50 \mu \mathrm{m}$ and $175 \mu \mathrm{m}$. While the bending strength is about $335.6 \mathrm{MPa}$, which is higher than the bending strength of using the $50 \mu \mathrm{m}$ and $175 \mu \mathrm{m} \mathrm{SiC} \mathrm{powders.} \mathrm{It} \mathrm{is} \mathrm{well}$ known that the bending strength of the ceramic materials

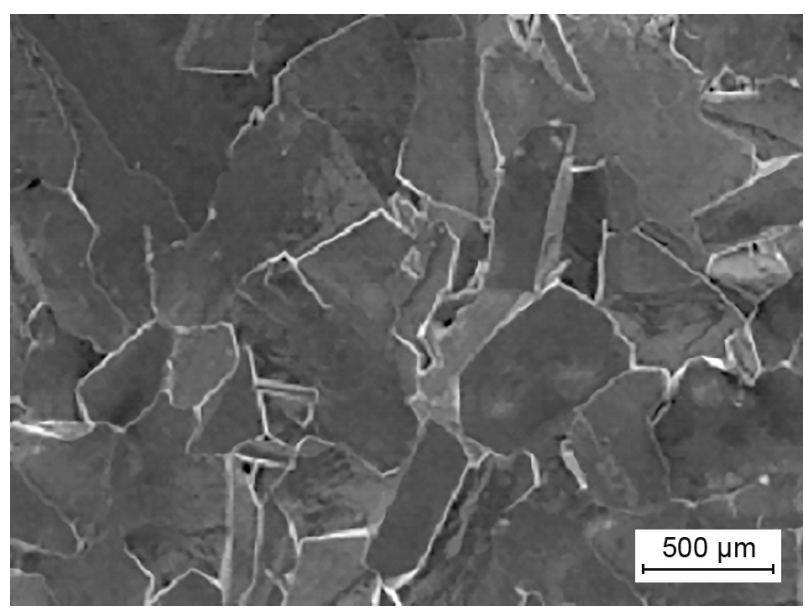

a) $500 \mathrm{~nm}$

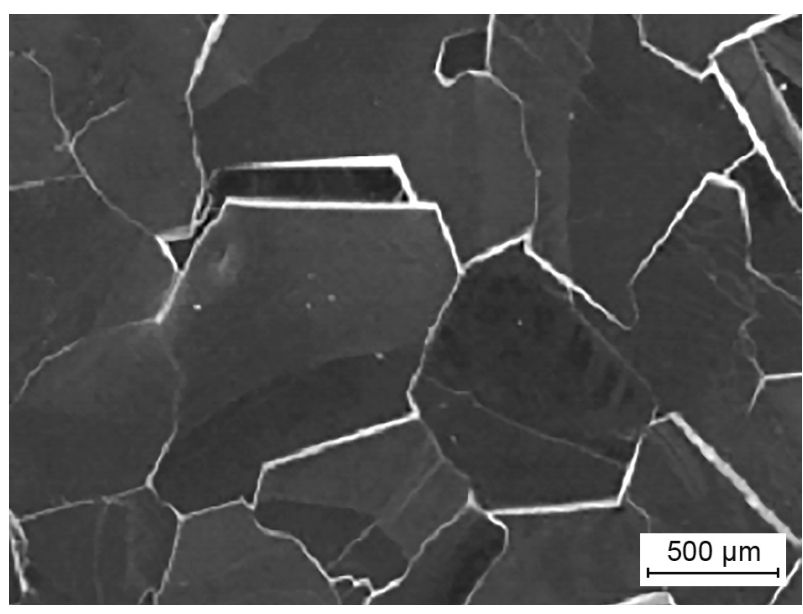

b) $50 \mu \mathrm{m}$

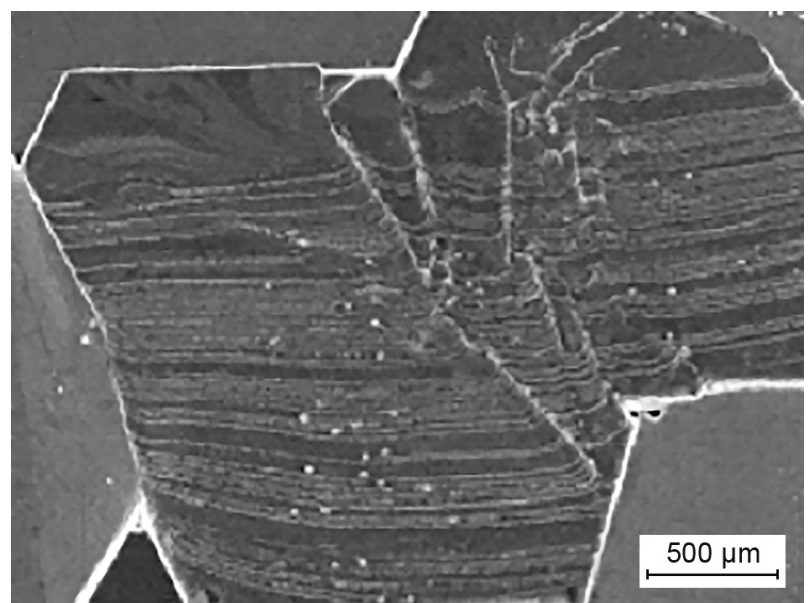

c) $175 \mu \mathrm{m}$

Figure 2. The SEM of the sample using the different size powders for growing $2 \mathrm{~h}$ : a) $500 \mathrm{~nm}$; b) $50 \mu \mathrm{m}$; c) $175 \mu \mathrm{m}$.

Table 2. The mechanical properties of the samples prepared at $2200^{\circ} \mathrm{C}$ for $120 \mathrm{~min}$.

\begin{tabular}{lccr}
\hline Size & $\begin{array}{c}\text { Bending } \\
(\mathrm{MPa})\end{array}$ & $\begin{array}{c}\text { Vickers hardness } \\
(\mathrm{GPa})\end{array}$ & $\begin{array}{c}\text { Density } \\
\left(\mathrm{g} \cdot \mathrm{cm}^{-3}\right)\end{array}$ \\
\hline $175 \mu \mathrm{m}$ & $290.0 \pm 7$ & $29.7 \pm 0.04$ & $3.10 \pm 0.005$ \\
$50 \mu \mathrm{m}$ & $311.1 \pm 5$ & $28.9 \pm 0.08$ & $3.08 \pm 0.006$ \\
$500 \mathrm{~nm}$ & $335.6 \pm 5$ & $28.5 \pm 0.08$ & $3.07 \pm 0.005$ \\
\hline
\end{tabular}

Ceramics - Silikáty 64 (2) 135-144 (2020) 
depends largely on the grain size and it decreased with an increase in the grain size, as explained by Carniglia using the Hall-Petch-type relationship [18-19]. In this study, the SiC grain size is mainly the reason which causes the low bending strength. Therefore, reducing the grain size is an important issue for improving the strength of the polycrystalline ceramics, and this will be investigated in the future. However, the Vickers hardness of the sample using $500 \mathrm{~nm}$ is lower than the samples using the 50 and $175 \mu \mathrm{m} \mathrm{SiC} \mathrm{powders.} \mathrm{The} \mathrm{reason} \mathrm{for} \mathrm{the}$ lower Vickers hardness is that the size of the indentation is $100 \mu \mathrm{m}$ (as shown in Figure 2), the basic grain size of the sample using $175 \mu \mathrm{m}$ is greater than $500 \mathrm{um}$, the indentation on the crack in the same grain; and the grain size of samples using $500 \mathrm{~nm}$ are less than $100 \mu \mathrm{m}$, with the grain boundary crack expanded, the indentation is very easy to extend.

The effects of the grain size on the nucleation density and growth rate of the $\mathrm{SiC}$ ceramics

Figure 3 shows the grain size of the $\mathrm{SiC}$ nuclei using the different raw materials for $2 \mathrm{~min}$ at $2200{ }^{\circ} \mathrm{C}$. It can be seen that the grain formed by the sub-micron powders is more uniform and smaller than that prepared by the other two raw materials. At the same time, the grain distribution of the sub-micron powders is more compact than that formed by the other two materials. However, the nucleation of the powder with the $75 \mu \mathrm{m}$ and $175 \mu \mathrm{m}$ particle sizes is dispersed and relatively larger, and the nucleation number is relatively smaller than that using the sub-micron powders as the raw material. The average grain size of the prepared material by using the sub-micron powders as the raw material is $33.13 \pm 0.008 \mu \mathrm{m}$ (Figure 3a), and the average grain size of the prepared material by using the other two raw materials is $40.79 \pm 0.006 \mu \mathrm{m}$ (Figure 3b) and $58.43 \pm 0.005 \mu \mathrm{m}$ (Figure $3 \mathrm{c}$ ), respectively. Because the sub-micron powders size is smaller, the surface area of the particles is larger, so the growth rate is faster than that prepared by the other two raw materials. Therefore, the compensates are the difference between the particle sizes of the raw materials, so that the grain size of the corresponding raw materials is so large, and the contact between the growth grains will be closer.

The principal stages during the PVT process were investigated based on the dissociative sublimation of the source material, the mass transport of the $\mathrm{Si}$ and $\mathrm{C}$ species to the substrate, and the deposition by condensation. The solid $\mathrm{SiC}$ was decomposed and could be interpreted by the following reactions:

$$
\begin{gathered}
\mathrm{SiC}(\text { solid }) \rightarrow \mathrm{SiC} \text { (gas) } \\
\mathrm{SiC}(\text { solid }) \rightarrow \mathrm{Si} \text { (gas) }+\mathrm{C}(\text { solid }) \\
2 \mathrm{SiC}(\text { solid }) \rightarrow \mathrm{SiC}_{2} \text { (gas) }+\mathrm{Si} \text { (gas) } \\
2 \mathrm{SiC}(\text { solid }) \rightarrow \mathrm{C}(\text { solid })+\mathrm{Si}_{2} \mathrm{C} \text { (gas) }
\end{gathered}
$$

When the $\mathrm{Si}$ (gas) and $\mathrm{SiC}_{2}$ (gas) diffuses to the edge of the substrate, it was easy to react with the carbon atoms on the graphite crucible lid and forms the $\mathrm{SiC}$ nuclei. Equations $1 \sim 4$ are the sublimation and decomposition reactions of the $\mathrm{SiC}$ powders in the crucible at the high temperature. The predominant species

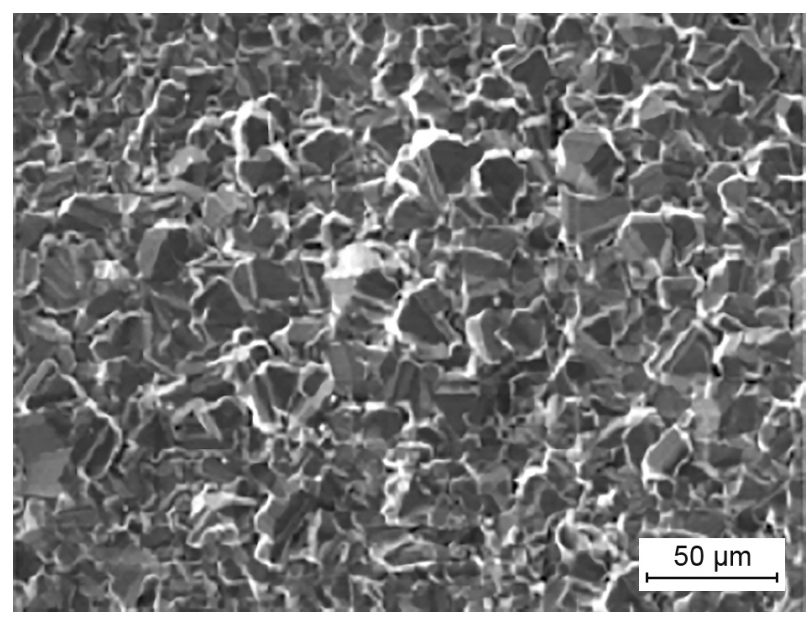

a) $500 \mathrm{~nm}$

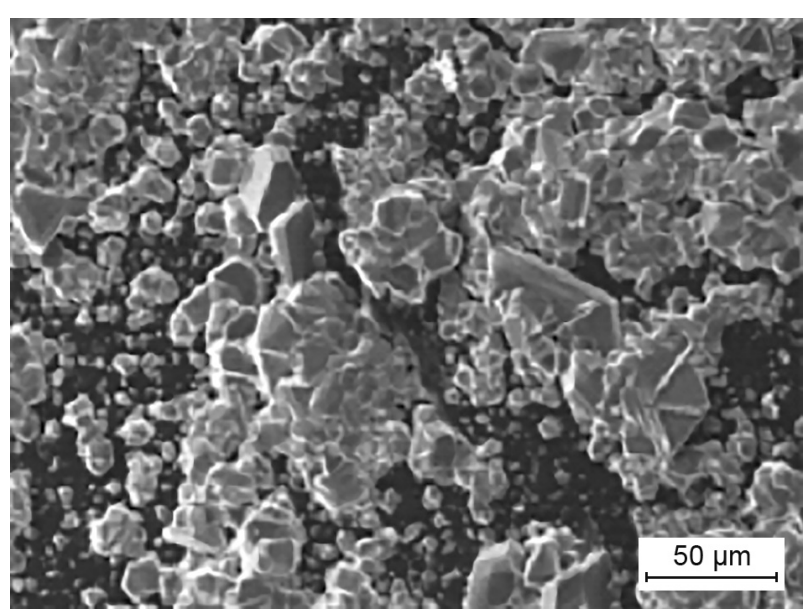

b) $50 \mu \mathrm{m}$

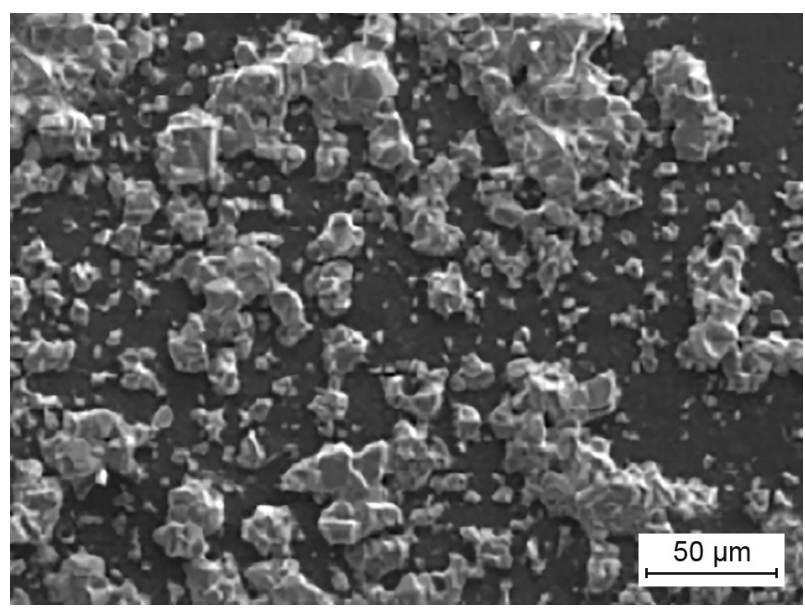

c) $175 \mu \mathrm{m}$

Figure 3. The SEM of the grain using the different size powders for growing 2 min: a) $500 \mathrm{~nm}$; b) $50 \mu \mathrm{m}$; c) $175 \mu \mathrm{m}$. 
in the sublimated vapour were: $\mathrm{Si}, \mathrm{SiC}_{2}$ and $\mathrm{Si}_{2} \mathrm{C}[20]$. The equilibrium partial pressures of $\mathrm{Si}, \mathrm{Si}_{2} \mathrm{C}$ and $\mathrm{SiC}_{2}$ were calculated at the different temperatures using [21]:

$$
\begin{aligned}
& \log p_{\mathrm{Si}}=12.74-2.66 \times \frac{10^{4}}{T} \\
& \log p_{\mathrm{Si}_{2} \mathrm{C}}=15.10-3.62 \times \frac{10^{4}}{T} \\
& \log p_{\mathrm{SiC}_{2}}=15.98-3.53 \times \frac{10^{4}}{T}
\end{aligned}
$$

Figure 4 displays equilibrium vapour pressure of the gas phases $\left(\mathrm{Si}, \mathrm{SiC}_{2}\right.$ and $\left.\mathrm{Si}_{2} \mathrm{C}\right)$ between $1950{ }^{\circ} \mathrm{C}$ and $2350{ }^{\circ} \mathrm{C}$. It can be seen that the pressure of three gases increased when the temperature increased, while the Si partial pressure increases at $1900-2200{ }^{\circ} \mathrm{C}$, and decreases above $2200{ }^{\circ} \mathrm{C}$. the gas mixture of the $\mathrm{Si}-\mathrm{C}$ in the Ar system, the mass transport was mostly driven by the temperature gradients, which lead to a difference in the vapour pressure between the source and the substrate [22]. The supersaturation of the vapour species is the driving force for the deposition of the vapour species at the growth front. The reaction between the $\mathrm{Si}$ or $\mathrm{Si}_{2} \mathrm{C}$ atoms in the vapour phase with the carbon atoms on the graphite crucible lid forms the $\mathrm{SiC}$ nuclei. The condensation and deposition of the Si partial pressure on the $\mathrm{SiC}$ in the crucible facilitates the growth of the $\mathrm{SiC}$ grains.

In addition, the relationship between the equilibrium vapour pressure and the grain size could be expressed as:

$$
\ln \frac{p}{p_{0}}=\frac{2 M \gamma}{R T d}
$$

where $P$ refers to the equilibrium vapour pressure of the source material with a diameter of $d, P_{0}$ is the bulk material equilibrium vapour pressure, $M$ is the material mole mass, and $\gamma$ is the surface energy and $R$ is the gas constant. According to Equation 8, when the grain size of the source material decreases, the equilibrium vapour

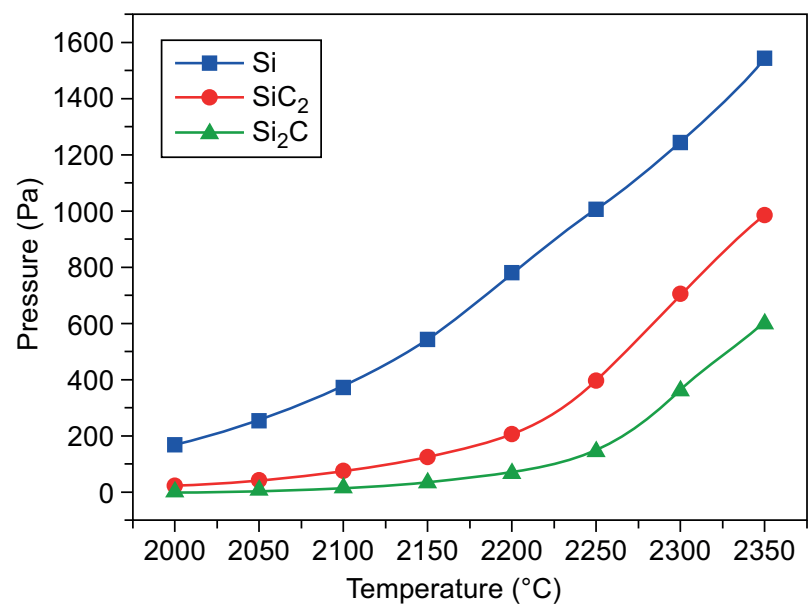

Figure 4. The equilibrium vapour pressure of the gas phase $\left(\mathrm{Si}, \mathrm{SiC}_{2}\right.$ and $\mathrm{Si}_{2} \mathrm{C}$ ) between $1950{ }^{\circ} \mathrm{C}$ and $2350{ }^{\circ} \mathrm{C}$. pressure would increase. Correspondingly, the difference in the partial vapour pressure among the vapour species would increase exponentially, which not only increases the absolute amount of the $\mathrm{C}$ component but also increases the $\mathrm{Si}-\mathrm{C}$ ratio. It may be responsible for the larger decreasing ratio of the sublimation rates and the higher recrystallisation rates for the smaller grain size of the source material. The calculated results proved that the grain size of the source material could affect the effective heat-transfer coefficient of the source material, the supersaturation, and the ratio of the $\mathrm{Si}: \mathrm{C}$ in the growth process of the $\mathrm{SiC}$ bulk single crystal by the PVT. Therefore, optimising the grain size of source material is an effective and convenient way to grow high-quality $\mathrm{SiC}$ bulk material in our experiment [23].

Figure 5 shows the grain size of $\mathrm{SiC}$ nuclei using the different raw materials at the different temperatures. The result shows the grain size of the $\mathrm{SiC}$ nuclei increased with the growth temperature lower than $2200^{\circ} \mathrm{C}$, and decreased with the growth temperature higher than $2200{ }^{\circ} \mathrm{C}$. While the grain size of the $\mathrm{SiC}$ nuclei increased with the increased size of the raw material, the grain size of the used sub-micron powder is more uniform than using the other raw material and has an average size between $11 \mu \mathrm{m} \sim 40 \mu \mathrm{m}$. However, the grain size of $50 \mu \mathrm{m}$ grade powder is between the $13 \mu \mathrm{m} \sim 80 \mu \mathrm{m}$ range larger and causes scattered nucleation, the grain size of the $175 \mu \mathrm{m}$ grade powder is in the range of $43 \mu \mathrm{m} \sim 110 \mu \mathrm{m}$. It is also reported that the proper temperature and the raw material were two key factors in the $\mathrm{SiC}$ growth region, the temperature guaranteed the evaporation of the raw materials to form the catalyst and promoted the nucleation and growth of $6 \mathrm{H}-\mathrm{SiC}$, while the raw vapour obtained by the heat radiation holes in the carbon fibre felt facilitated the transportation and transition of the vapour specials [19]. In addition, it can also be found in the figure that the size of the grain size is associated with the particle size of the raw materials at the same temperature.

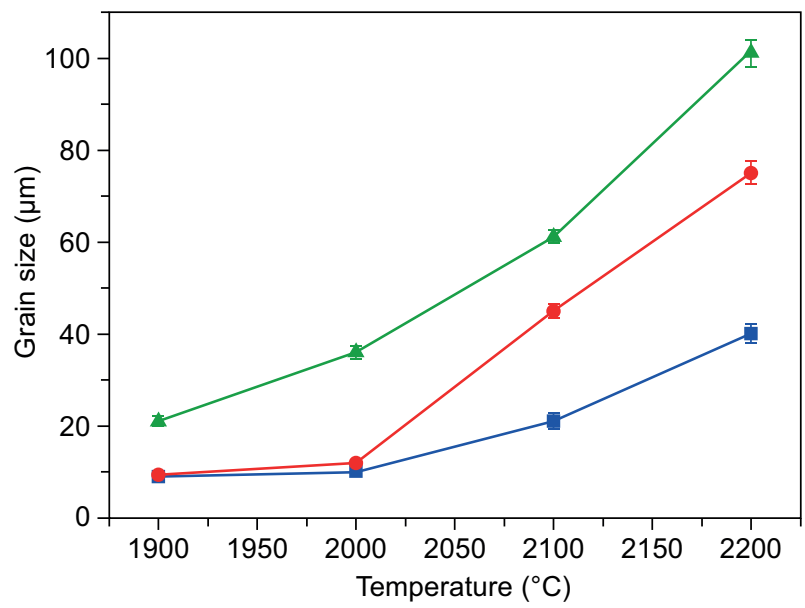

Figure 5. The grain size of the $\mathrm{SiC}$ nuclei using the different raw materials at the different temperature. 
Figure 6 shows the growth rate of the $\mathrm{SiC}$ using the different raw materials for $30 \mathrm{~min}$ at the different temperatures, where the growth rate is the ratio of the thickness and the growth time by preparing a thick sheet to be measured, reducing the raw material silicon carbide. At different temperatures, the growth rate of the same powders was firstly increased and then decreased when the growth temperature was above $2200{ }^{\circ} \mathrm{C}$. This phenomenon is different from the report by Dai [17], where they found the growth rate increases with the increasing temperature and temperature gradient. They thought the main factors influencing the growth rate of the $\mathrm{SiC}$ ceramics were the temperature and the temperature gradient. But in our experiment, there no temperature gradient exists, the vapour transmission path in the powders may play an important role in the growth process, as when the temperature increases the Si atoms on the substrate surface reacts to the evaporation, the $\mathrm{Si}$

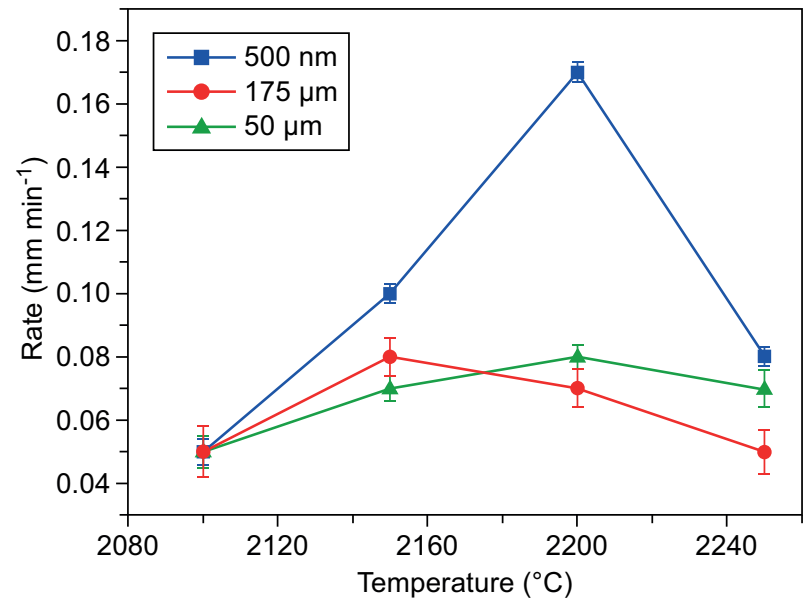

Figure 6. The growth rate of the $\mathrm{SiC}$ at the different sintering temperatures using the different raw materials.

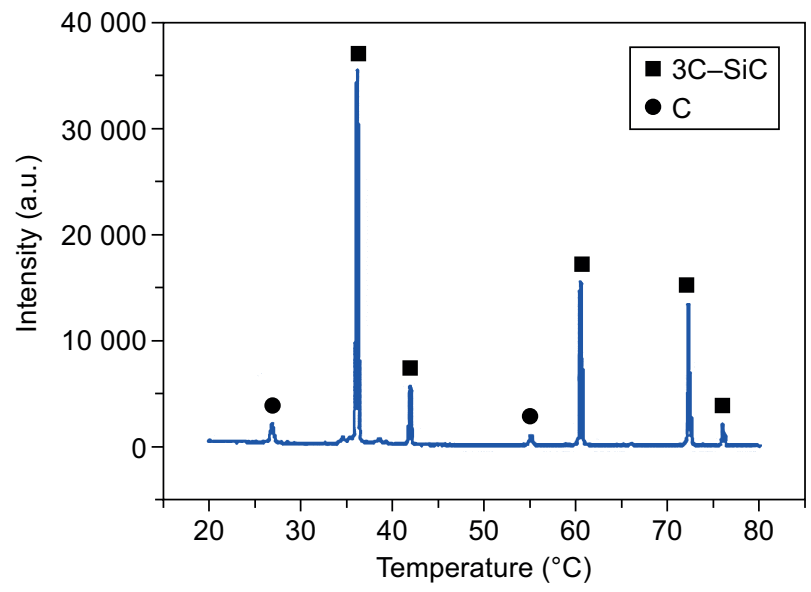

a) $1900^{\circ} \mathrm{C}$ atoms over the substrate surface vapour and the pressure decreases, so the growth rate gradually decreases. The growth rate of the $500 \mathrm{~nm}$ powder was the quickest. With the increasing temperature from $2100{ }^{\circ} \mathrm{C}$ to $2250{ }^{\circ} \mathrm{C}$, the maximum value of the growth rate using the $500 \mathrm{~nm}$ powder was $0.17 \mathrm{~mm} \cdot \mathrm{min}^{-1}$ at $2200^{\circ} \mathrm{C}$, this is larger than using the $50 \mu \mathrm{m}$ and $175 \mu \mathrm{m}$ powder, whose maximum value is $0.075 \mathrm{~mm} \cdot \mathrm{min}^{-1}$ and $0.075 \mathrm{~mm} \cdot \mathrm{min}^{-1}$, respectively. On the other hand, it is difficult to exactly test the density of the sample obtained at a time less than $30 \mathrm{~min}$. In the initial stage, the crystal growth is mainly in nucleation, the bulk $\mathrm{SiC}$ materials were difficult to obtain for short times. On the other hand, the purpose of this paper is to investigate the densification process of the polycrystalline $\mathrm{SiC}$ by the PVT method, the sample is not compact when the time is less than $30 \mathrm{~min}$, and the main work is focused on the nucleation process emphatically at the period.

The effects of the sintering temperature on the crystal type and growth morphology of the $\mathrm{SiC}$ ceramic using the $500 \mathrm{~nm}$ powder

Figure 7 shows that the XRD patterns of the SiC ceramic grows $60 \mathrm{~min}$ at the different sintering temperature using the sub-micron $\mathrm{SiC}$ powder as a raw material. When the growth temperature is at $1900{ }^{\circ} \mathrm{C}$, the silicon carbide crystal is mainly $3 \mathrm{C}-\mathrm{SiC}$, with the growth temperature increased at $2100^{\circ} \mathrm{C}$, the characteristic diffraction peaks of the sample is $3 \mathrm{C}-\mathrm{SiC}$ and $6 \mathrm{H}-\mathrm{SiC}$. The phase can be identified as pure $\alpha$-SiC $(6 \mathrm{H})$ above $2200{ }^{\circ} \mathrm{C}$. The peaks at $2 \mathrm{~h}=35.6^{\circ}$ and $75.4^{\circ}$, corresponding to the

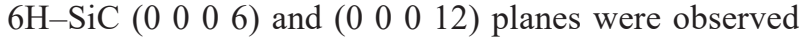
in all the samples. Additionally, with an increasing temperature, the relative intensities of the peaks corresponding to the $\left(\begin{array}{llll}0 & 0 & 0 & 1\end{array}\right)$ planes significantly increased from 9000 to 28000 , whereas the relative intensities of the other peaks gradually weakened.

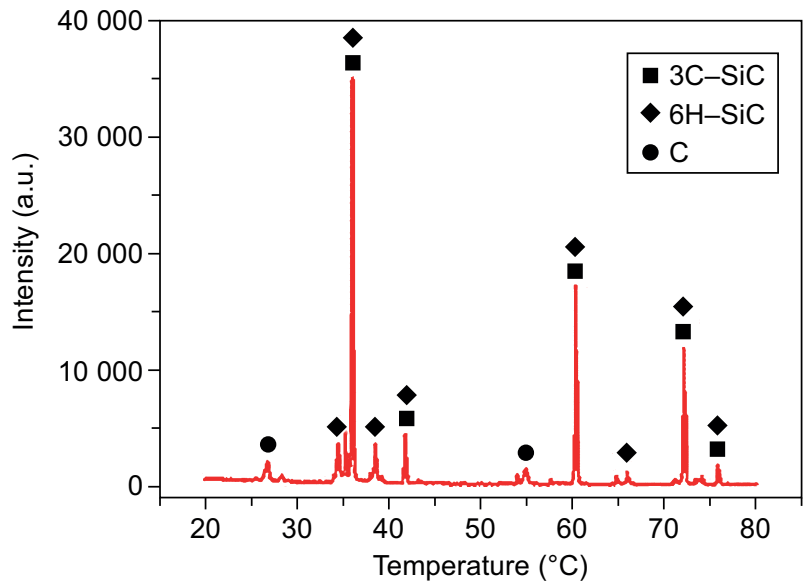

b) $2000^{\circ} \mathrm{C}$

Figure 7. The XRD patterns of the $\mathrm{SiC}$ ceramic at the different sintering temperatures using the sub-micrometre-SiC powder as a raw material: a) $1900{ }^{\circ} \mathrm{C}$, b) $2000{ }^{\circ} \mathrm{C}$ ). (Continue on next page) 


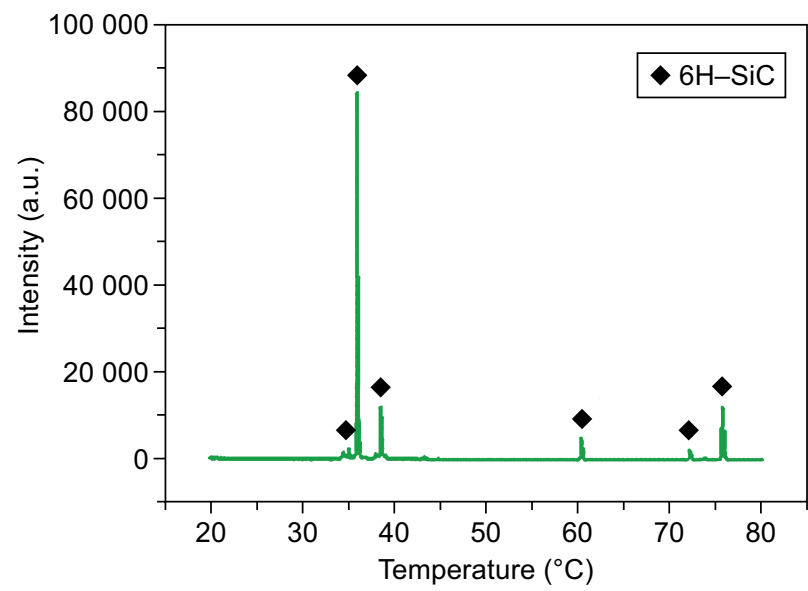

c) $2100^{\circ} \mathrm{C}$

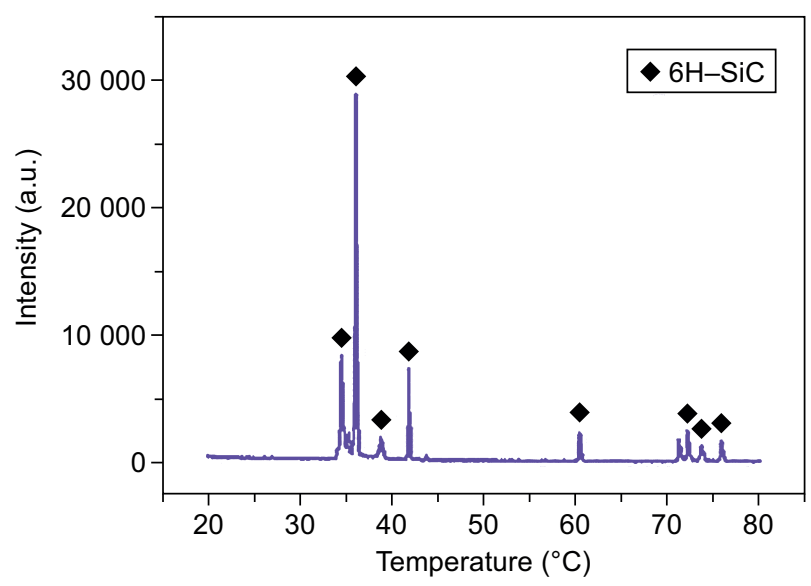

d) $2200{ }^{\circ} \mathrm{C}$

Figure 7. The XRD patterns of the $\mathrm{SiC}$ ceramic at the different sintering temperatures using the sub-micrometre-SiC powder as a raw material: c) $2100{ }^{\circ} \mathrm{C}$, d) $2200{ }^{\circ} \mathrm{C}$ ).

Figure 8 shows the $\mathrm{SEM}$ of the $\mathrm{SiC}$ grains obtained using the $500 \mathrm{~nm}$ powders grown at the different temperatures $\left(1900{ }^{\circ} \mathrm{C}, 2000{ }^{\circ} \mathrm{C}, 2100{ }^{\circ} \mathrm{C}, 2200{ }^{\circ} \mathrm{C}\right)$ for $2 \mathrm{~min}$. It can be seen that the number of the $\mathrm{SiC}$ grain size is relatively small in the samples grown at $1900{ }^{\circ} \mathrm{C}$ and the graphite substrates can also be seen. With the growth temperature increasing, the size of the grains increases gradually, and the graphite substrates disappear. It can be found that the morphology of the silicon carbide grains has developed to be hexagonal over $2100{ }^{\circ} \mathrm{C}$, the regular columnar silicon carbide grains with the typical characteristics of $\alpha$-SiC grains can be clearly seen. Because the nucleation rate of the silicon carbide raw material is higher and the growth rate is lower at lower temperatures, thus the number of grains observed is more and the size is smaller. With the increasing temperature, the nucleation rate decreases and the growth rate increases, so the number of grains observed decreases and the size increases.

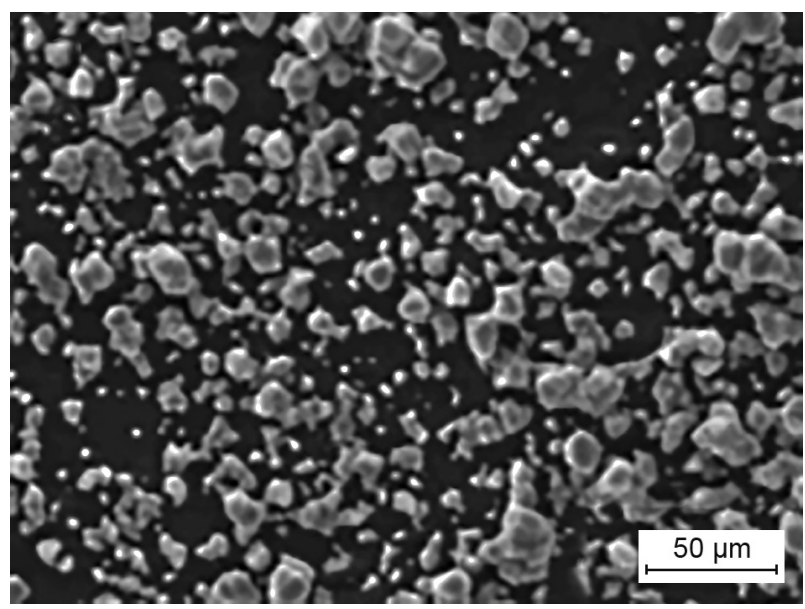

a) $1900^{\circ} \mathrm{C}$
Figure 9 show the SEM of the sample using the $500 \mathrm{~nm}$ powders growing at different times: $2 \mathrm{~min}$; $8 \mathrm{~min} ; 32 \mathrm{~min} ; 60 \mathrm{~min}$. It can be seen that the grain size is much smaller, and the large number of grains at $2200{ }^{\circ} \mathrm{C}$ for $2 \mathrm{~min}$, the grains were arranged having a stacked manner existence and were relatively dense. With the holding time being increased, the grain size is relatively large, and the number of grains decreased, along with the growth of the grain orientation, the growth is about to begin, generating voids which appeared between the grains. When growth time is over $32 \mathrm{~min}$, the crystal along the $\left(\begin{array}{llll}0 & 0 & 0 & 1\end{array}\right)$ surface orientation grows, the voids between the grains gradually increase, mainly due to the directional growth process, the other plane growth is slower, with the growth process of the crystal growth, the grain boundary diffusion gap between the grain boundaries decreases, and densified sintering at $60 \mathrm{~min}$.

Figure 8. The SEM of the $\mathrm{SiC}$ grains growth obtained at the different temperatures: a) $\left.1900{ }^{\circ} \mathrm{C}, \mathrm{b}\right) 2000{ }^{\circ} \mathrm{C}$. (Continue on next page) 


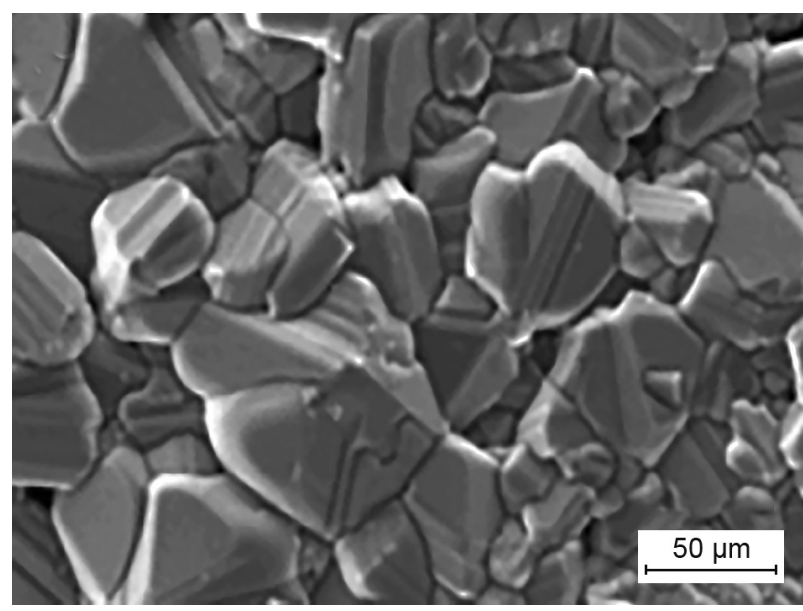

c) $2100^{\circ} \mathrm{C}$

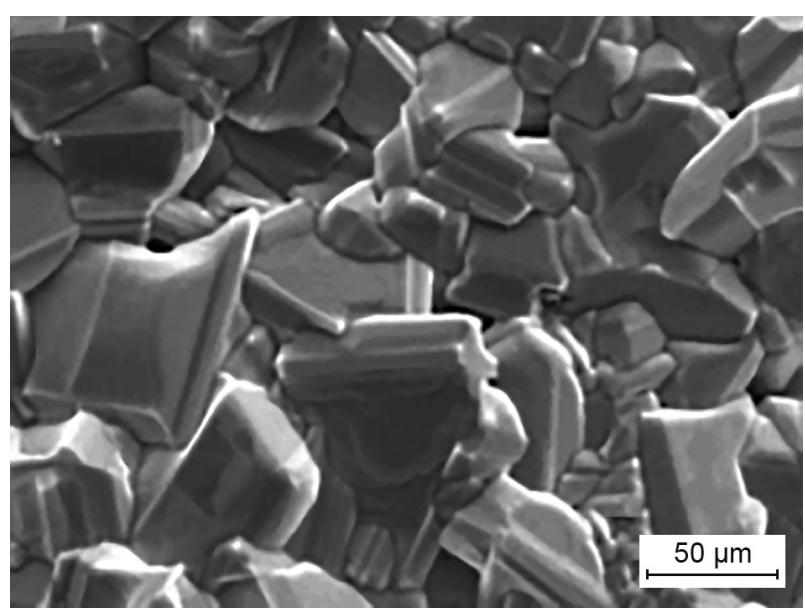

d) $2200^{\circ} \mathrm{C}$

Figure 8. The SEM of the $\mathrm{SiC}$ grains growth obtained at the different temperatures: c) $\left.2100{ }^{\circ} \mathrm{C}, \mathrm{d}\right) 2200{ }^{\circ} \mathrm{C}$.

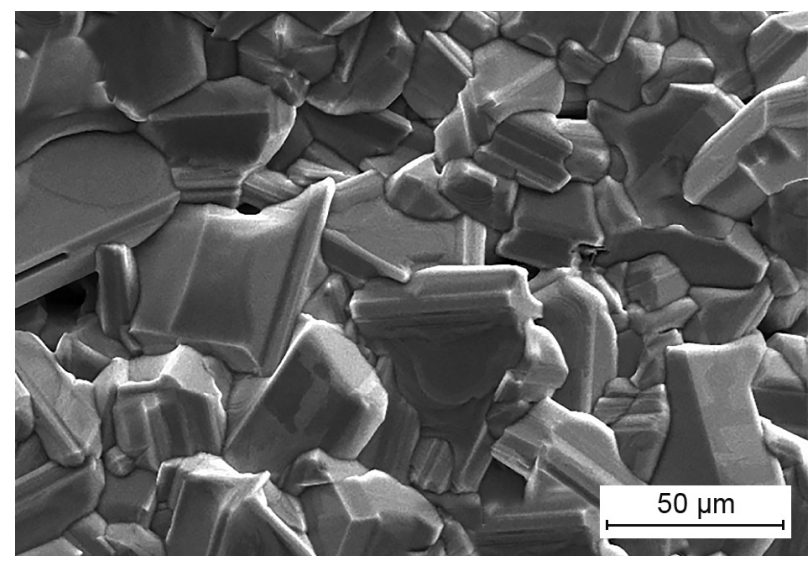

a) $2 \mathrm{~min}$

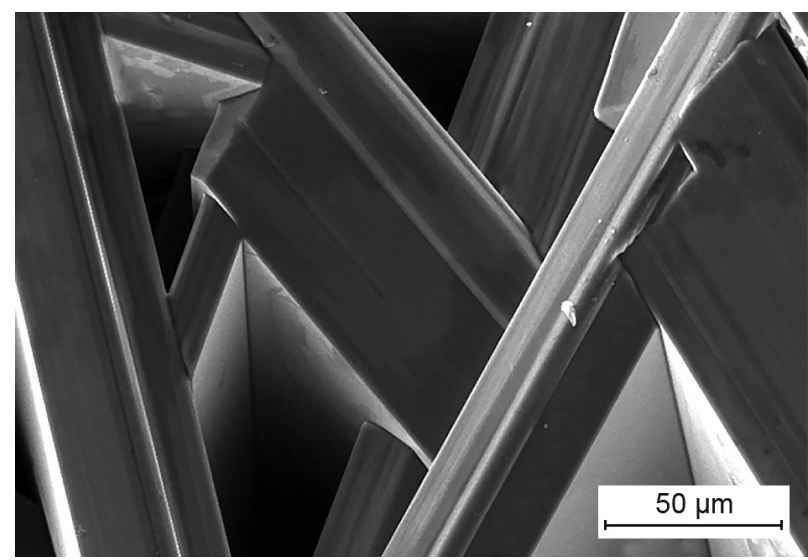

c) $32 \mathrm{~min}$

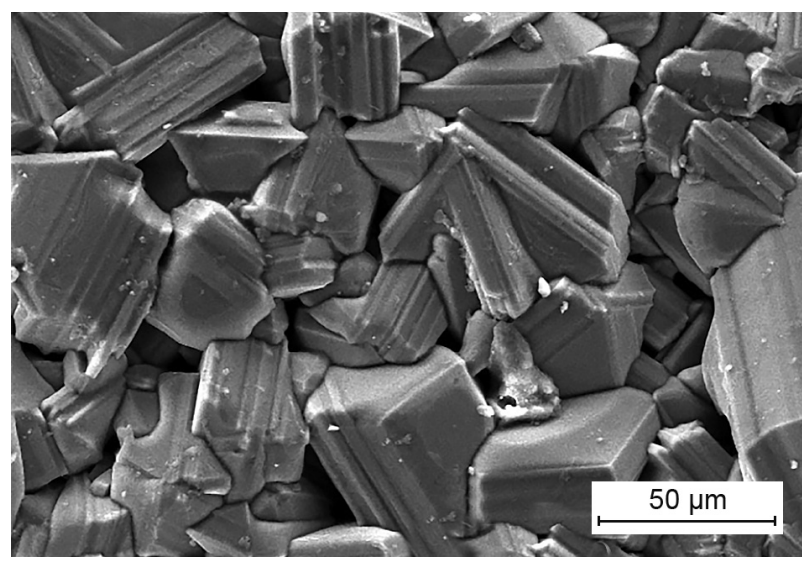

b) $8 \mathrm{~min}$

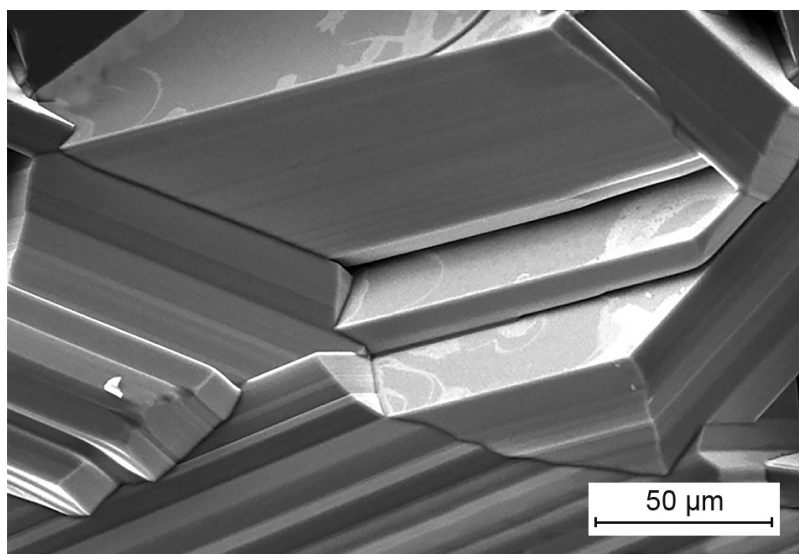

d) $6 \mathrm{~min}$

Figure 9. The SEM of the samples using $500 \mathrm{~nm}$ powders for the different growing time: a) $2 \mathrm{~min}$; b) $8 \mathrm{~min}$; c) $32 \mathrm{~min}$; d) $60 \mathrm{~min}$.

\section{CONCLUSIONS}

Dense SiC was prepared by a high-temperature physical vapour transport (PVT) method using sub-micron $\mathrm{SiC}$ powders $(500 \mathrm{~nm})$ as a raw material. The effects of the temperature and holding time on the grain size, growth rate, thickness and orientation of the silicon carbide were explored, and the concentration gradient, random nuclei of the $\mathrm{SiC}$ on the polycrystalline phase growth during the SiC PVT growth were studied. The growth mechanism was explained from the thermodynamics and kinetics perspective. The result shows the grain size of the $\mathrm{SiC}$ nuclei increased with a growth temperature lower than $2200^{\circ} \mathrm{C}$, and decreased with a growth temperature higher 
than $2200{ }^{\circ} \mathrm{C}$. The XRD analysis shows the majority of the silicon carbide crystal $\beta$-SiC $(3 \mathrm{C}-\mathrm{SiC})$ with a growth temperature lower at $2000{ }^{\circ} \mathrm{C}$, and it is $6 \mathrm{H}-\mathrm{SiC}$ above $2200{ }^{\circ} \mathrm{C}$. From the 2000 to $2200{ }^{\circ} \mathrm{C}$ temperature range, the $3 \mathrm{C}-\mathrm{SiC}$ decreases, but the $6 \mathrm{H}-\mathrm{SiC}$ increases, while in this temperature range, the transition was from the $3 \mathrm{C}-\mathrm{SiC}$ to the $6 \mathrm{H}-\mathrm{SiC}$ phase. The microstructure shows that the growth of the silicon carbide has hexagonal columnar silicon carbide grains above $2200{ }^{\circ} \mathrm{C}$, the average grain size of the $\mathrm{SiC}$ material is $100 \mu \mathrm{m}$, while the characteristics of the $\alpha$-SiC grains is obvious. The silicon carbide ceramics exhibited a bending strength of only $335.6 \mathrm{MPa}$, a bulk density of $3.07 \mathrm{~g} \cdot \mathrm{cm}^{-3}$ and a Vickers hardness of $28.5 \pm 0.6 \mathrm{GPa}$.

\section{Acknowledgments}

This work was funded by the National Natural Science Foundation of China (NSFC, Grant No. 51672209), by the National Key R\&D Program of China (Grant No. 2017YFB0310300), and the Natural Science Basic Research Plan in Shaanxi Province of China (Grant No. 2016JQ5046).

\section{REFERENCES}

1. Lee S. K., Kim Y. C., Kim C. H. (1994): Microstructural development and mechanical properties of pressurelesssintered $\mathrm{SiC}$ with plate-like grains using $\mathrm{Al}_{2} \mathrm{O}_{3}-\mathrm{Y}_{2} \mathrm{O}_{3}$ additives. Journal of Materials Science, 29(20), 5321-5326. Doi: 10.1007/BF01171542

2. Ravi B. G., Omotoye O. A., Srivatsan T. S., Petrorali M., Sudarshan, T. S. (2000): The microstructure and hardness of silicon carbide synthesized by plasma pressure compaction. Journal of Alloys and Compounds, 299(1-2), 292-296. Doi: 10.1016/S0925-8388(99)00815-4

3. Fernández J. M., Munoz A., de Arellano López A. R., Feria F. V., Dominguez-Rodriguez A., Singh M. (2003): Microstructure - mechanical properties correlation in siliconized silicon carbide ceramics. Acta Materialia, 51(11), 3259-3275. Doi: 10.1016/S1359-6454(03)00157-5

4. Zhou T., Xu R., Ruan B., Liang Z., Wang X. (2018): Fabrication of microlens array on $6 \mathrm{H}-\mathrm{SiC}$ mold by an integrated microcutting-etching process. Precision Engineering, 54, 314-320. Doi: 10.1016/j.precisioneng.2018. 06.008

5. Racka K., Tymicki E., Grasza K., Jakieła R., Pisarek M., Surma B., Avdonin A., Skupinski P., Krupka J. (2014): Growth of SiC by PVT method with different sources for doping by a cerium impurity, $\mathrm{CeO}_{2}$ or $\mathrm{CeSi}_{2}$. Journal of Crystal Growth, 401, 677-680. Doi: 10.1016/j.jcrysgro. 2014.02.041

6. Jun H. W., Lee H. W., Song H., Kim B. H., Ha J. (2004): Reaction-bonded silicon carbide tube fabricated by continuous sintering of double-walled preform. Ceramics International, 30(4), 533-537. Doi: 10.1016/j.ceramint.2003. 09.022
7. Zhang X. F., Yang Q., De Jonghe L. C. (2003): Microstructure development in hot-pressed silicon carbide: effects of aluminum, boron, and carbon additives. Acta Materialia, 51(13), 3849-3860. Doi: 10.1016/S1359-6454(03)00209-X

8. Yuan R., Kruzic J. J., Zhang X. F., De Jonghe L. C., Ritchie R. O. (2003): Ambient to high-temperature fracture toughness and cyclic fatigue behavior in Al-containing silicon carbide ceramics. Acta Materialia, 51(20), 6477-6491. Doi: 10.1016/j.actamat.2003.08.038

9. Jung E., Kim, Y., Kwon Y. J., Lee C. Y., Lee M. H., Lee W. J., ... \& Jeong S. M. (2018): Synthesis of V-doped SiC powder for growth of semi-insulating SiC crystals. Ceramics International, 44(18), 22632-22637. Doi: 10.1016/ j.ceramint.2018.09.039

10. Racka K., Tymicki E., Grasza K., Kowalik I. A., Arvanitis D., Pisarek M., et al. (2013): Growth of SiC by PVT method in the presence of cerium dopant. Journal of Crystal Growth, 377, 88-95. Doi: 10.1016/j.jcrysgro.2013.05.011

11. Gallardo-López A., Muñoz A., Martınez-Fernández J., Domınguez-Rodriguez A. (1999). High-temperature compressive creep of liquid phase sintered silicon carbide. Acta Materialia, 47(7), 2185-2195. Doi: 10.1016/S13596454(99) 00072-5

12. Guo X., Yang H., Zhang L., Zhu X. (2010): Sintering behavior, microstructure and mechanical properties of silicon carbide ceramics containing different nano-TiN additive. Ceramics International, 36(1), 161-165. Doi: 10.1016/ j.ceramint.2009.07.013

13. Cupid D. M., Fabrichnaya O., Seifert H. J. (2007): Thermodynamic aspects of liquid phase sintering of $\mathrm{SiC}$ using $\mathrm{Al}_{2} \mathrm{O}_{3}$ and $\mathrm{Y}_{2} \mathrm{O}_{3}$. International Journal of Materials Research, 98(10), 976-986. Doi: 10.3139/146.101557

14. Kim Y. W., Lee S. H., Nishimura T., Mitomo M. (2005): Heat-resistant silicon carbide with aluminum nitride and scandium oxide. Acta Materialia, 53(17), 4701-4708. Doi: 10.1016/j.actamat.2005.07.002

15. Shiramomo T., Gao B., Mercier F., Nishizawa S., Nakano S., Kakimoto K. (2014): Study of the effect of doped impurities on polytype stability during PVT growth of SiC using 2D nucleation theory. Journal of Crystal Growth, 385, 95-99. Doi: 10.1016/j.jcrysgro.2013.03.036

16. Shiramomo T., Gao B., Mercier F., Nishizawa S., Nakano S., Kangawa Y., Kakimoto K. (2012): Thermodynamical analysis of polytype stability during PVT growth of $\mathrm{SiC}$ using 2D nucleation theory. Journal of Crystal Growth, 352(1), 177-180. Doi: 10.1016/j.jcrysgro.2012.01.023

17. Dai P. Y., Wang Y. Z., Liu G. L., Wang B., Shi Y. G., Yang J. F., et al. (2011): Fabrication of highly dense pure SiC ceramics via the HTPVT method. Acta Materialia, 59(16), 6257-6263. Doi: 10.1016/j.actamat.2011.06.035

18. Lilov S. K. (1995). Thermodynamic analysis of phase transformations at the dissociative evaporation of silicon carbide polytypes. Diamond and Related Materials, 4(12), 1331-1334. Doi: 10.1016/0925-9635(95)00312-6

19. Shi Y., Yang J., Liu H., Dai P., Liu B., Jin Z., et al. (2012): Fabrication and mechanism of 6H-type silicon carbide whiskers by physical vapor transport technique. Journal of Crystal Growth, 349(1), 68-74. Doi: 10.1016/j. jcrysgro.2012.03.055

20. Lin L., Zhu L., Zhao R., Tao H., Huang J., Zhang Z. (2019): Ferromagnetism induced by vacancies in $(\mathrm{N}, \mathrm{Al})$-codoped 6H-SiC. Solid State Communications, 288, 28-32. Doi: 10.1016/j.ssc.2018.11.009 
21. Van Rijswijk W., Shanefield D. J. (1990): Effects of carbon as a sintering aid in silicon carbide. Journal of the American Ceramic Society, 73(1), 148-149. Doi: 10.1111/j.11512916.1990.tb05109.x

22. Lilov S. K. (1993): Study of the equilibrium processes in the gas phase during silicon carbide sublimation. Materials Science and Engineering: B, 21(1), 65-69. Doi: 10.1016/0921-5107(93)90267-Q
23. Shi Y., Dai P., Yang J., Jin Z., Cheng J., Liu H. (2012): Effects of Grain Size of Source Material on Growing $6 \mathrm{H}-\mathrm{SiC}$ Bulk Crystal by Physical Vapor Transport. Materials and Manufacturing Processes, 27(1), 84-87. Doi: $10.1080 / 10426914.2010 .544829$ 